\title{
Do people's perceptions and attitudes associate with enrollment in health insurance in a context of Nepal?
}

\author{
Devaraj Acharya $^{1^{*}}$, Bhimsen Devkota $^{2}$, Radha Bhattarai $^{1}$ \\ *Corresponding author, e-mail: $\underline{\text { drabmc@gmail.com. }}$
}

\begin{abstract}
The Government of Nepal introduced the health insurance [HI] program in three districts, in 2016 and now has been expanded almost all districts. Since it was a new initiative, there was no clear evidence on people's attitude, perception, and awareness, which continues until now. This study, therefore, intended to assess the perception and attitude of household heads towards enrollment in $\mathrm{HI}$.
\end{abstract}

The descriptive research design was used and 810 households in Baglung and Kailali Districts of Nepal were selected randomly. The interview schedule used for data collection comprised positive and negative statements at a three-point scale as independent variables to explore the perception and attitude of people towards $\mathrm{HI}$ and enrollment in $\mathrm{HI}$ as a dependent variable.

Most of the respondents agreed with the statement where attitude and perception were significantly associated with the enrollment in $\mathrm{HI}$. Among the 16 statements, 13 statements were observed statistically significant. Among them: 'anyone can enroll easily in $\mathrm{HI}^{\prime}$, 'primary service point is appropriate', 'contribution amount is appropriate', 'coverage amount is appropriate', 'HI may solve the problem', 'proper dissemination of information, education, communication [IEC] materials may help to enroll', 'health services quality has not been improved after enrollment', 'IEC materials are not appropriate', 'HI related queries are addressed timely', 'relatives/neighbors do/did not request me to enroll', 'complaints are not addressed timely', and 'information is not adequate' were the significantly associated for enrollment in HI.

The perception and attitude of the household heads were significantly associated with the enrollment in $\mathrm{HI}$. The study recommends an appropriate IEC campaign for positive perception and attitudes that leads to better participation in $\mathrm{HI}$. The policymaker may consider the findings while planning the program intervention.

\section{Keywords: Attitude, Enrollment, Health Insurance, Perception}

\section{Introduction}

Health insurance $(\mathrm{HI})$ is a financial protection and pre-payment system for healthcare services. $\mathrm{HI}$ aims to minimize the gap of the utilization of health care between 'haves' and 'haves not' due to financial constrain. The Government of Nepal (GoN) introduced the health insurance program (HIP) in 2016 in three

\footnotetext{
${ }^{1}$ Bhairahawa Multiple Campus, Rupandehi, Nepal

${ }^{2}$ Mahendra Ratna Campus, Tribhuvan University, Kathmandu, Nepal
} 
districts of Nepal (Acharya, 2020). And, now the program reached almost all districts except Kathmandu and Bhaktapur. However most of the people were unknown and only one out of ten people had adequate knowledge about it (KOICA-Nepal Health Insurance Support Project [NHISP], 2014). Since the HIP is recently introduced and a novel idea for Nepalese people, they may have misperception and misinterpretation regarding $\mathrm{HI}$ which may prevent them to enroll. In such instances, people's perception and attitude could be a matter for the success of the program.

'Attitude is a small thing but makes a great difference' is a well-known saying that exists in our society (Ballon \& Skinner, 2008). Attitude influences behavior. People generally do not want to change because good behaviour is generally time-consuming, inconvenient, complicated, and even less awarded (Water Aid, n.d.). Adequate information is needed for making a positive attitude and perception. Perception towards the program could have a greater impression (Amo-adjei et al., 2016). A study in Kailali shows that only 11 percent of people had heard about health insurance [HI] whereas, only nine percent had good knowledge about it (KOICA-Nepal Health Insurance Support Project [NHISP], 2014).

Nepalese people are yet to be well-informed about $\mathrm{HI}$. The concept of $\mathrm{HI}$ is relatively new for Nepal. People are still less known and aware of it (KOICA-Nepal Health Insurance Support Project [NHISP], 2014). Though, United Mission to Nepal had initiated the HI program as Lalitpur Medical Insurance Scheme in 1976. It could not be continued due to a lack of political commitment (KOICA/HIMAL Project, 2012). A study from Kenya shows that having knowledge regarding $\mathrm{HI}$ is positively associated with uptake of $\mathrm{HI}$ (Maina et al., 2016). Not having proper information may lead to negative perception resulting in poor enrollment in $\mathrm{HI}$.

It is claimed that lack of having knowledge of $\mathrm{HI}$ is associated with poor utilization of health care services and delayed the health-seeking behaviour leading to the deterioration of the health condition and productivity as well (Nadpara, 2009). A study from Jordan indicates that parents of differently-abled persons, who had $\mathrm{HI}$, were satisfied but not very much satisfied with the HI services available to them (Altarawneh et al., 2017) which means they were seeking quality health care services. It is supposed that enrollment in HI may protect people from catastrophic health care costs while receiving health services (Maina et al., 2016).

People expect quality health services from health care providers. There are eight dimensions of quality assurance: technical competence; access to services; service effectiveness; human relationship; service efficiency; service continuity; security; and amenities-hygiene/cleanliness (Agustin \& Laksmono, 2019). Without a positive attitude or perception, even quality health services become worthless though they are being provided appropriately. Little or inadequate information on $\mathrm{HI}$ may lead to unwillingness toward enrollment and negative perception towards HI (Maina et al., 2016).

After the implementation of the social health security program in Nepal, the study has been conducted to find the people's perception and attitude on HI whether people are familiar or not with the program. Therefore, the study aims to examine the association between the people's perception and attitude, and their enrollment in $\mathrm{HI}$. 


\section{Literature review}

Attitudes toward HI may be positive even knowledge remains poor (Adewole et al., 2015). However, a high level of knowledge on $\mathrm{HI}$ usually leads positive attitude and a higher level of education may not lead to higher enrollment in $\mathrm{HI}$ but higher knowledge on $\mathrm{HI}$ results in higher enrollment (Acharya et al., 2019). Misconception and misinformation lead to bad attitudes as well as perception which might result in poor enrollment on $\mathrm{HI}$ so a good understanding is a key to ensuring acceptance and participation (Agyei-baffour et al., 2013). It does not always mean that higher education and wealth status are more likely to enroll. A study from Ghana shows that the poorest men and uneducated women were more likely to enroll in $\mathrm{HI}$ compared to rich and educated men and women (Dixon et al., 2013).

A low level of perception and attitude about $\mathrm{HI}$ creates moral hazards. People may ask for health services even they are not sick. That kind of attitude and perception makes the program unsuccessful (Maina et al., 2016). Adequate information regarding $\mathrm{HI}$ must be needed for making a positive effort. A study conducted at Sunsari district on community-based HI shows that just more than half [54\%] of the enrolled members were satisfied with the HI program (Subedi et al., 2018).

Socio-demographic characteristics of the subscribers such as residence setting, age, wealth status, and access to media influence the perceived quality of services provided to them in Ghana (Nketiah-Amponsah et al., 2019). 'Attitude does make big differences' even in decision making for treatment-seeking and acceptance of the recommendation of physicians (Orr et al., 2008, p. 150). A study carried out in India shows that treatment seeking for dental care was associated with $\mathrm{HI}$ and correlated with patients' acceptance. Where patient's acceptance was associated with patient's positive perception (Joshi et al., 2019). Patients' satisfaction also depends upon the patient's perception and attitude towards the expectation and services provided to them (Otto-sobotka et al., 2019).

Positive attitude and perception, and satisfaction with health services truly support and even sustain the enrollment in HI. Perception towards the program and quality services could have a great impression on the enrollment (Amo-adjei et al., 2016). HI program needs national solidarity especially from the political level, public support, and people's acceptance. Without a positive attitude and perception, and quality health services, it is not possible to operate the HI program successfully. Individuals' characters such as age, health status, perception and socio-demographic factors of the family are significantly associated with the enrollment in HI. Therefore, perception towards insurance is one of the significant predictors for enrollment (Mathur et al., 2015).

People may enroll in $\mathrm{HI}$ if they believe the program is potentially beneficial and perceiving of economic benefit (Dixon et al., 2013). Adequate information, education, and communication could lead to a positive attitude and perception and a higher chance of being enrolled (Adewale et al., 2016). A study undertaken in India shows that individual perception toward $\mathrm{HI}$ is associated with enrollment (Mathur et al., 2015). We could not find any study regarding perception and attitude and its association with the enrollment of $\mathrm{HI}$ in the context of Nepal. Therefore, the study aimed to find out whether there was any association between the individual perception and attitude towards $\mathrm{HI}$ and enrollment. 


\section{Methods}

\section{Research design}

The study used a cross-sectional survey design.

Variables

In this study, socio-demographic characteristics of the respondents, and attitudes and perception towards the $\mathrm{HI}$ were taken as independent variables and enrollment in $\mathrm{HI}$ was the dependent variable. In the socio-demographic features, some attributes such as caste/ethnicity [Dalit, Madhesi, Muslim, Dasnami, Thakuri as 'others'], religion [Buddhist, Islam and Christian as 'others'], mother tongue [Doteli Aachhami, and others as 'others'], and wealth status [as rich, middle and poor] of the variables were merged due to poor responses though these variables were not further analyzed.

\section{Sample and sampling method}

The sample size was calculated by Daniel's formula (Acharya et al., 2019; Naing et al., 2006) adjusting five percent non-response rate as observed in the Nepal Demographic and Health Survey (Ministry of Health et al., 2017) and fifty-fifty prevalence probability of perception and attitude and its association with the enrollment (Acharya et al., 2020; Kothari, 2004).

Sample size $(n)=\left[z^{2} p(1-p)\right] / d^{2}$ and then, adjusted $n=[n /$ expected response rate $]=405$

[Where the level of confidence was 95\%, response rate 95\%, and margin of error 5\%]

The sample size was 405 for both the enrolled family and the non-enrolled family. Therefore, the total sample was 810 families. The list of the enrolled households was obtained from Health Insurance Board [HIB], Districts Offices in Baglung and Kailali districts respectively. The sample was selected by using a simple random sampling method for enrolled households and proximal households were taken for non-enrolled households assuming that proximal households have similar access and utilization of healthcare services. The same method was applied for non-enrolled household samples if more than one household appeared in the proximity of enrolled households. The households enrolled from other organizations than HIB were excluded throughout the research process.

\section{Research tool}

The interview schedule was used for data collection. For the validation of the tool, a total of five percent $[42=21+21]$ of the total sample were pre-tested in Palpa District. Cronbach's alpha was calculated $[$ Alpha $=0.734]$ and which was eligible to administer since the score was more than 0.70 which means 73 percent of the variance was reliable (Hair et al., 2014). The attributes of the response of statements were managed as agree, neutral, and disagree [whatever the nearness].

\section{Collection of data}

A household-based survey was conducted in Baglung and Kailali Districts of Nepal where the program was initially implemented by the government of Nepal. Data were collected mostly from household heads. All enrolled households were the population of the study. The interview schedule [IS] was administered to collect the data predominantly from the household heads where they felt convenient to respond. In case of rejection or absence of household heads for responses, another member of household was requested. The IS consisted 
of socio-demographic characteristics of individuals and households, and Likert's type three-point scale statements where one for disagree, two for neutral, and three for agree; for positive, and exactly reverse for negative statements respectively.

\section{Analysis of data}

Data were inspected, and edited before entry. We used IBM SPSS Statistics 20 software to analyze the data. Univariate, bivariate and multivariate analyses were used to interpret the data as per the study objective. But only univariate analysis was performed for socio-demographic characteristics of households and individuals.

\section{Ethical approval}

For ethical consideration, consent was taken before interviewing the respondents. The research proposal was reviewed for ethical approval from Nepal Health Research Council [Ref. 1807, Reg. no. 473/2017] and approved. The information obtained from the respondents was kept confidential as per the research ethics and guidelines (Nepal Health Research Council, 2011).

\section{Results}

\section{Socio-demographic characteristics of the respondents}

Since the study was conducted in Baglung and Kailali Districts of Nepal, a total of 70 percent [566] of the household were assigned from Kailali and remains 30 percent [244] were from Baglung District as per the population proportion observed in the census 2011 (Central Bureau of Statistics, 2014).

Table 1: Socio-demographic characteristics of the respondents ( $n=810)$

\begin{tabular}{llcc}
\hline Character & Category & $\%$ & No. \\
\hline District & Baglung & 30.1 & 244 \\
& Kailali & 69.9 & 566 \\
\hline Residence setting & Urban & 74.1 & 600 \\
& Rural & 25.9 & 210 \\
\hline Sex of respondents & Male & 49.0 & 397 \\
& Female & 51.0 & 413 \\
\hline Household head & No & 34.1 & 276 \\
& Yes & 65.9 & 534 \\
\hline The age group of respondents & Up to 25 years & 15.1 & 122 \\
& 26 to 50 years & 65.6 & 531 \\
& More than 50 years & 19.4 & 157 \\
\hline Caste/Ethnicity of respondents & Aadibasi/Janajatis & 43.5 & 352 \\
& Brahmin/Chhetry & 36.2 & 293 \\
& Others & 20.4 & 165 \\
\hline Religion & Hindu & 91.2 & 739 \\
& Others & 8.8 & 71 \\
\hline Native language & Nepali & 58.3 & 472 \\
& Tharu & 29.8 & 241 \\
& Others & 12.0 & 97 \\
\hline
\end{tabular}




\begin{tabular}{llcc}
\hline Character & Category & $\%$ & No. \\
\hline Literacy status & Illiterate & 7.4 & 60 \\
& Literate & 92.6 & 750 \\
\hline Type of family & Nuclear & 41.0 & 332 \\
& Joint & 59.0 & 478 \\
\hline Size of family & Up to 5 members & 56.4 & 457 \\
& More than 5 members & 43.6 & 353 \\
\hline Wealth status & Poor & 33.3 & 270 \\
& Middle & 33.3 & 270 \\
& Rich & 33.3 & 270 \\
\hline Ability to feed & Throughout the year & 51.2 & 415 \\
& 6 to 11 months & 18.6 & 151 \\
& Less than 6 months & 30.1 & 244 \\
\hline The family member having chronic & No & 65.4 & 530 \\
diseases & Yes & 34.6 & 280 \\
\hline
\end{tabular}

Source: Field Survey, 2021

Out of the total respondents, 74 and 26 percent were from urban [municipality] and rural [rural municipality] areas. More than half [51\%] of the respondents were female and two-third were household heads. Sixty percent of the respondents' age was between 21 to 40 years and the median and mean age of the respondents were 37 and $39 \pm 13$ years respectively. Forty-four percent of the respondents were Aadibasi/Janajatis and 36 percent belonged to Brahmin/Chhetry. Most of the respondents [91\%] were Hindu. Thirty percent of the respondents spoke the Tharu language as their mother tongue and 58 percent of the respondents spoke the Nepali language as their mother tongue. Almost all [93\%] respondents were literate. The median and average size of the family were five and $5.6 \pm 19$ respectively with a minimum of two to a maximum of 14 members. The wealth status of households was divided into 33 percent each from rich, middle and poor. Nearly half [49\%] of the respondents could not feed their families throughout the year. Nearly twothirds of households [65\%] had at least one family member having chronic diseases.

\section{Respondents' attitude and perception towards health insurance}

There were 16 statements related to $\mathrm{HI}$. Among them, nine statements were positive and seven statements were negative. The respondents had to respond as disagree, unknown/neutral and agree which would be carrying one, two, and three scores respectively for positive statements and exactly opposite for negative statements. Most of the statements' results seemed as agreed except for the statement 'HI related queries are addressed in time'. Fifty-eight percent of the respondents agreed with the statement 'anyone can easily enroll in $\mathrm{HI}$ or there is no problem to enroll' and the mode of the statement was agreed [3] with a composite score of 1900 [2.35]. In the same way, 46 percent of the respondents agreed with the statement 'primary service point is suitable for me' with a score of 1713 [2.11] and the mode of the statement was 'agree' [3]. Fifty-five percent of the respondents agreed with the statement 'contribution amount for $\mathrm{HI}$ is appropriate' which score was 1898[2.34] and the mode of the statement was 'agree' [3]. 
The statement 'coverage amount of HI was appropriate' was agreed by 54 percent of the respondents with a score of 1891[2.33] and the mode of the statement was 'agree' [3]. More than half [53\%] of the respondents agreed with the statement 'my family is susceptible to diseases and health problems which score was 1933[2.39] and mode 'agree' [3]. Nearly three fourth [74\%] of the respondents were found to agree with the statement 'there may be financial loss and other problems if any of my family members become sick' with the score of 2153[2.66] and the mode was 'agree' [3]. However, more than one-third [36\%] of the respondents expressed that they neither agreed nor disagreed with the statement 'enrollment in $\mathrm{HI}$ may solve aforementioned problems' yielding a total score of 1669 [2.06] and the mode was 'neutral' [2]. Sixty-three percent of the respondents agreed the statement 'proper dissemination of information, education, and communication materials may help to enroll in HI' with a total score of 2017[2.49] and the mode of the statement was 'agree' [3].

Table 2: Respondents' perceptions regrading health insurance program

\begin{tabular}{|c|c|c|c|c|c|c|c|c|c|}
\hline \multirow{2}{*}{ Positive Statements $(n=810)$} & \multicolumn{2}{|c|}{ Disagree (1) } & \multicolumn{2}{|c|}{ Neutral (2) } & \multicolumn{2}{|c|}{ Agree (3) } & \multirow{2}{*}{ 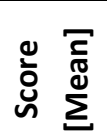 } & \multirow{2}{*}{$\stackrel{\frac{0}{0}}{\frac{0}{0}}$} & \multirow{2}{*}{ 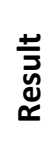 } \\
\hline & No. & $\%$ & No. & $\%$ & No. & $\%$ & & & \\
\hline $\begin{array}{l}\text { Anyone can easily enroll in } \mathrm{HI} \text { or there is } \\
\text { no problem to enroll. }\end{array}$ & 189 & 23.3 & 152 & 18.8 & 469 & 57.9 & $\begin{array}{c}1900 \\
(2.35)\end{array}$ & $\begin{array}{c}3 \\
{[A]}\end{array}$ & $A$ \\
\hline $\begin{array}{l}\text { Primary service point is suitable for } \\
\text { me. }\end{array}$ & 280 & 34.6 & 157 & 19.4 & 373 & 46.0 & $\begin{array}{c}1713 \\
(2.11)\end{array}$ & $\begin{array}{c}3 \\
{[A]}\end{array}$ & $A$ \\
\hline $\begin{array}{l}\text { The contribution amount for } \mathrm{HI} \text { is } \\
\text { appropriate. }\end{array}$ & 164 & 20.2 & 204 & 25.2 & 442 & 54.6 & $\begin{array}{c}1898 \\
(2.34)\end{array}$ & $\begin{array}{c}3 \\
{[A]}\end{array}$ & A \\
\hline $\begin{array}{l}\text { The coverage amount for } \mathrm{HI} \text { is } \\
\text { appropriate. }\end{array}$ & 162 & 20.0 & 215 & 26.5 & 433 & 53.5 & $\begin{array}{c}1891 \\
(2.33)\end{array}$ & $\begin{array}{c}3 \\
{[A]}\end{array}$ & $A$ \\
\hline $\begin{array}{l}\text { My family is susceptible to diseases or } \\
\text { health problems. }\end{array}$ & 113 & 14.0 & 271 & 33.5 & 426 & 52.6 & $\begin{array}{c}1933 \\
(2.39)\end{array}$ & $\begin{array}{c}3 \\
{[A]}\end{array}$ & A \\
\hline $\begin{array}{l}\text { There may be financial loss or other } \\
\text { problems if any of my family members } \\
\text { become sick. }\end{array}$ & 63 & 7.8 & 151 & 18.6 & 596 & 73.6 & $\begin{array}{l}2153 \\
(2.66)\end{array}$ & $\begin{array}{c}3 \\
{[A]}\end{array}$ & $A$ \\
\hline $\begin{array}{l}\text { Enrollment in } \mathrm{HI} \text { may solve } \\
\text { aforementioned problems. }\end{array}$ & 235 & 29.0 & 291 & 35.9 & 284 & 35.1 & $\begin{array}{c}1669 \\
(2.06)\end{array}$ & $\begin{array}{c}2 \\
{[N]}\end{array}$ & $A$ \\
\hline $\begin{array}{l}\text { Proper dissemination of IEC materials } \\
\text { may help to enroll in HI. }\end{array}$ & 113 & 14.0 & 187 & 23.1 & 510 & 63.0 & $\begin{array}{r}2017 \\
(2.49) \\
\end{array}$ & $\begin{array}{c}3 \\
{[A]}\end{array}$ & $A$ \\
\hline $\begin{array}{l}\mathrm{HI} \text { related queries are addressed in } \\
\text { time. }\end{array}$ & 361 & 44.6 & 281 & 34.7 & 168 & 20.7 & $\begin{array}{c}1427 \\
(1.76)\end{array}$ & $\begin{array}{c}1 \\
{[D]}\end{array}$ & $\mathrm{D}$ \\
\hline Negative Statements $(n=810)$ & \multicolumn{2}{|c|}{ Agree (1) } & \multicolumn{2}{|c|}{ Neutral (2) } & \multicolumn{2}{|c|}{ Disagree (3) } & & & \\
\hline $\begin{array}{l}\text { The health service quality provided by } \\
\text { the GoN is not satisfactory. }\end{array}$ & 311 & 38.4 & 244 & 30.1 & 255 & 31.5 & $\begin{array}{c}1564 \\
(1.93)\end{array}$ & $\begin{array}{c}1 \\
{[A]}\end{array}$ & A \\
\hline $\begin{array}{l}\text { Health services quality has not been } \\
\text { improved after the HI program } \\
\text { launched }\end{array}$ & 330 & 40.7 & 265 & 32.7 & 215 & 26.5 & $\begin{array}{l}1505 \\
(1.86)\end{array}$ & $\begin{array}{c}1 \\
{[A]}\end{array}$ & A \\
\hline $\begin{array}{l}\text { Existing IEC materials for } \mathrm{HI} \text { are not } \\
\text { appropriate and sufficient. }\end{array}$ & 379 & 46.8 & 229 & 28.3 & 202 & 24.9 & $\begin{array}{c}1443 \\
(1.78)\end{array}$ & $\begin{array}{c}1 \\
{[A]}\end{array}$ & $A$ \\
\hline
\end{tabular}




\begin{tabular}{|c|c|c|c|c|c|c|c|c|c|}
\hline \multirow{2}{*}{ Positive Statements $(n=810)$} & \multicolumn{2}{|c|}{ Disagree (1) } & \multicolumn{2}{|c|}{ Neutral (2) } & \multicolumn{2}{|c|}{ Agree (3) } & \multirow{2}{*}{ 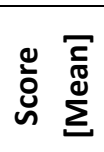 } & \multirow{2}{*}{$\stackrel{\frac{0}{0}}{\frac{0}{\Sigma}}$} & \multirow{2}{*}{ 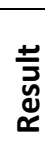 } \\
\hline & No. & $\%$ & No. & $\%$ & No. & $\%$ & & & \\
\hline $\begin{array}{l}\text { HI related complaints are not } \\
\text { addressed in time. }\end{array}$ & 400 & 49.4 & 249 & 30.7 & 161 & 19.9 & $\begin{array}{c}1381 \\
(1.70)\end{array}$ & $\begin{array}{c}1 \\
{[A]}\end{array}$ & A \\
\hline $\begin{array}{l}\text { It is not easy to take health services } \\
\text { even after enrollment. }\end{array}$ & 422 & 52.1 & 220 & 27.2 & 168 & 20.7 & $\begin{array}{c}1366 \\
(1.69)\end{array}$ & $\begin{array}{c}1 \\
{[A]}\end{array}$ & A \\
\hline $\begin{array}{l}\text { Relatives or friends did not } \\
\text { request/discuss for enrollment. }\end{array}$ & 358 & 44.2 & 110 & 13.6 & 342 & 42.2 & $\begin{array}{c}1604 \\
(1.98)\end{array}$ & $\begin{array}{c}1 \\
{[A]}\end{array}$ & A \\
\hline $\begin{array}{l}\text { HI-related information is not adequate } \\
\text { from communication media. }\end{array}$ & 383 & 47.3 & 196 & 24.2 & 231 & 28.5 & $\begin{array}{c}1468 \\
(1.81)\end{array}$ & $\begin{array}{c}1 \\
{[A]}\end{array}$ & A \\
\hline
\end{tabular}

Note: $A_{=}$Statement agreed by respondents, $N=$ Neutral, and $D_{=}$Statement disagreed by respondents

However, 45 percent of the respondents disagreed with the statement ' $\mathrm{HI}$ related queries are addressed timely with the score of $1427[1.76]$ and the mode was 'disagree'[1]. All the respondents agreed to all seven negative statements. However, the scores of the statements were different. Thirty-eight percent of the respondents agreed with the statement 'health service quality provided by the government of Nepal is not satisfactory' with a score of 1564[1.93] and the mode of the statement was 'agree'[1]. Forty-one percent of the respondents agreed with the statement 'health service quality has not been improved even after launching of HI program' with a score of1505[1.86] and the mode was 'agree'[1]. Nearly half [47\%] of the respondents agreed to the statement 'existing information, education, and communication materials for $\mathrm{HI}$ are not appropriate and sufficient' which score was 1443[1.78] with mode 'agree'[1]. In the same way, 49 percent of the respondents also agreed with the statement 'HI related complaints are not addressed timely' with a score of $1381[1.70]$ and the mode was 'agree'[1].

More than half [52\%] of the respondents agreed to the statement 'it is not easy to receive health services even after enrollment' with a score of 1366[1.67] with a mode 'agree'[1]. In the same way, more than half [54\%] of the respondents were found to agree with the statement 'relatives or friends did not request/discuss for enrollment' which score was 1604[1.98] and the mode of the statement was 'agree'[1]. Less than half [47\%] of the respondents agreed with the statement 'HI related is not adequate from communication media' with the score of $1468[1.81]$ and the mode was 'agree'[1].

\section{Association of people's attitude and perception with enrollment in health insurance}

Almost all statements were associated with the enrollment in $\mathrm{HI}$ and 13 out of 16 statements were statistically significant in bivariate analysis. Sixty-three percent of the respondents who agreed with the statement 'anyone can easily enroll in $\mathrm{HI}$ or there is no problem to enroll' were enrolled compared to 42 percent of those who disagreed with that statement $(p<0.001)$. Similarly, 60 percent of the respondents were enrolled and agreed with the statement 'primary service point is suitable for me' against 46 percent of those enrolled but disagreed with that statement $(p<0.001)$. In the same way, 60 percent of the respondents who agreed the statement of 'contribution amount of $\mathrm{HI}$ is appropriate' were enrolled compared to 43 percent of those who disagreed with that statement $(p<0.001)$. Fifty-nine percent of the respondents who agreed to the statement 'coverage amount for $\mathrm{HI}$ is appropriate' were enrolled compared to 46 percent of those who disagreed with that statement $(p<0.001)$. The majority of the respondents agreed with the statements 'my 
family is susceptible to diseases or health problems'; 'there may be financial loss and other problems if any of my family members become sick'; and 'proper dissemination of information, education and communication materials may help to enroll in health insurance' but not statistically significant.

Fifty-nine percent of the respondents who agreed with the statement 'enrollment in HI may solve aforementioned problems' were enrolled compared to 53 percent of those who disagreed with that statement $(p<0.001)$. But, 57 percent of the respondents who disagreed with the statement 'health service quality provided by the government of Nepal is not satisfactory' were enrolled compared to 51 percent of those who agreed with that statement $(p<0.001)$. Nearly two-third [65\%] of the respondents who disagreed with the statement 'health services quality has not been improved even after $\mathrm{HI}$ program launched' were enrolled compared to 52 percent of those who agreed on that statement $(p<0,001)$. Likewise, 58 percent of the respondents who disagreed with the statement 'existing information, education, and communication materials for $\mathrm{HI}$ are not appropriate and sufficient' were enrolled compared to 52 percent of those who agreed with that statement $(p<0.001)$. A two third [67\%] of the respondents who agreed to the statement 'HI-related queries are addressed timely' were enrolled compared to 49 percent of those who disagreed with that statement $(p<0.001)$.

Fifty-eight percent of the respondents who disagreed with the statement of 'HI related complaints are not addressed timely' were enrolled compared to 52 percent of those who agreed with that statement $(p<0.001)$. Similarly, fifty-nine percent of the respondents who disagreed with the statement 'it is not easy to take health services even after enrollment' were enrolled compared to 54 percent of those who agreed with that statement $(p<0.001)$. In the same way, 64 percent of the respondents who disagreed with the statement of 'relatives or friends did not request/discuss for enrollment' were enrolled compared to 39 percent of those who agreed with that statement $(p<0.001)$. Likewise, 60 percent of the respondents who disagreed with the statement of ' $\mathrm{HI}$ related information is not adequate from communication media' were enrolled compared to 49 percent of those who agreed with that statement $(p<0.001)$. 
Table 3: Respondents' feelings and perception towards health insurance and enrollment in health insurance cross tabulation

\begin{tabular}{|c|c|c|c|c|c|c|c|}
\hline \multirow[t]{3}{*}{ Statements } & \multirow{3}{*}{$\begin{array}{l}\text { Response } \\
\text { Category }\end{array}$} & \multicolumn{4}{|c|}{ Enrollment in health insurance } & \multirow{3}{*}{ 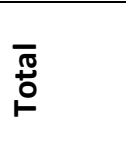 } & \multirow{3}{*}{$\begin{array}{l}\frac{0}{2} \\
\frac{\pi}{\pi} \\
2\end{array}$} \\
\hline & & \multicolumn{2}{|c|}{ No } & \multicolumn{2}{|c|}{ Yes } & & \\
\hline & & $\mathbf{N}$ & $\%$ & $\mathbf{N}$ & $\%$ & & \\
\hline \multirow{3}{*}{$\begin{array}{l}\text { Anyone can easily enroll in } \mathrm{HI} \text { or there is no problem to } \\
\text { enroll. }\end{array}$} & Disagree & 110 & 58.2 & 79 & 41.8 & 189 & \multirow{3}{*}{$<0.001$} \\
\hline & Neutral & 122 & 80.3 & 30 & 19.7 & 152 & \\
\hline & Agree & 173 & 36.9 & 296 & 63.1 & 469 & \\
\hline \multirow{3}{*}{ The primary service point is suitable for me. } & Disagree & 151 & 53.9 & 129 & 46.1 & 280 & \multirow{3}{*}{$<0.001$} \\
\hline & Neutral & 106 & 67.5 & 51 & 32.5 & 157 & \\
\hline & Agree & 148 & 39.7 & 225 & 60.3 & 373 & \\
\hline \multirow{3}{*}{ The contribution amount for $\mathrm{HI}$ is appropriate. } & Disagree & 94 & 57.3 & 70 & 42.7 & 164 & \multirow{3}{*}{$<0.001$} \\
\hline & Neutral & 136 & 66.7 & 68 & 33.3 & 204 & \\
\hline & Agree & 175 & 39.6 & 267 & 60.4 & 442 & \\
\hline \multirow{3}{*}{ The coverage amount for $\mathrm{HI}$ is appropriate. } & Disagree & 87 & 53.7 & 75 & 46.3 & 162 & \multirow{3}{*}{$<0.001$} \\
\hline & Neutral & 139 & 64.7 & 76 & 35.3 & 215 & \\
\hline & Agree & 179 & 41.3 & 254 & 58.7 & 433 & \\
\hline \multirow{3}{*}{ My family is susceptible to diseases or health problems. } & Disagree & 58 & 51.3 & 55 & 48.7 & 113 & \multirow{3}{*}{0.121} \\
\hline & Neutral & 148 & 54.6 & 123 & 45.4 & 271 & \\
\hline & Agree & 199 & 46.7 & 227 & 53.3 & 426 & \\
\hline \multirow{3}{*}{$\begin{array}{l}\text { There may be financial loss and other problems if any of } \\
\text { my family members become sick. }\end{array}$} & Disagree & 30 & 47.6 & 33 & 52.4 & 63 & \multirow{3}{*}{0.115} \\
\hline & Neutral & 87 & 57.6 & 64 & 42.4 & 151 & \\
\hline & Agree & 288 & 48.3 & 308 & 51.7 & 596 & \\
\hline \multirow{3}{*}{$\begin{array}{l}\text { Enrollment in } \mathrm{HI} \text { may solve the aforementioned } \\
\text { problems. }\end{array}$} & Disagree & 111 & 47.2 & 124 & 52.8 & 235 & \multirow{3}{*}{$<0.001$} \\
\hline & Neutral & 177 & 60.8 & 114 & 39.2 & 291 & \\
\hline & Agree & 117 & 41.2 & 167 & 58.8 & 284 & \\
\hline \multirow{3}{*}{$\begin{array}{l}\text { Proper dissemination of IEC materials may help to enroll } \\
\text { in } \mathrm{HI} \text {. }\end{array}$} & Disagree & 53 & 46.9 & 60 & 53.1 & 113 & \multirow{3}{*}{0.266} \\
\hline & Neutral & 103 & 55.1 & 84 & 44.9 & 187 & \\
\hline & Agree & 249 & 48.8 & 261 & 51.2 & 510 & \\
\hline \multirow{2}{*}{$\begin{array}{l}\text { The health service quality provided by the GoN is not } \\
\text { satisfactory. }\end{array}$} & Agree & 151 & 48.6 & 160 & 51.4 & 311 & \multirow[b]{2}{*}{$<0.001$} \\
\hline & Neutral & 145 & 59.4 & 99 & 40.6 & 244 & \\
\hline
\end{tabular}




\begin{tabular}{|c|c|c|c|c|c|c|c|}
\hline \multirow[t]{4}{*}{ Statements } & \multirow{3}{*}{$\begin{array}{l}\text { Response } \\
\text { Category }\end{array}$} & \multicolumn{4}{|c|}{ Enrollment in health insurance } & \multirow{3}{*}{$\begin{array}{l}\overline{5} \\
\stackrel{0}{0}\end{array}$} & \multirow{3}{*}{$\begin{array}{l}\frac{0}{3} \\
\frac{\pi}{\pi} \\
2\end{array}$} \\
\hline & & \multicolumn{2}{|c|}{ No } & \multicolumn{2}{|c|}{ Yes } & & \\
\hline & & $\mathbf{N}$ & $\%$ & $\mathbf{N}$ & $\%$ & & \\
\hline & Disagree & 109 & 42.7 & 146 & 57.3 & 255 & \\
\hline \multirow{3}{*}{$\begin{array}{l}\text { The health services quality has not been improved after } \\
\text { the HI program launched. }\end{array}$} & Agree & 158 & 47.9 & 172 & 52.1 & 330 & \multirow{3}{*}{$<0.001$} \\
\hline & Neutral & 171 & 64.5 & 94 & 35.5 & 265 & \\
\hline & Disagree & 76 & 35.3 & 139 & 64.7 & 215 & \\
\hline \multirow{3}{*}{$\begin{array}{l}\text { Existing IEC materials for } \mathrm{HI} \text { are not appropriate and } \\
\text { sufficient. }\end{array}$} & Agree & 177 & 46.7 & 202 & 53.3 & 379 & \multirow{3}{*}{$<0.001$} \\
\hline & Neutral & 144 & 62.9 & 85 & 37.1 & 229 & \\
\hline & Disagree & 84 & 41.6 & 118 & 58.4 & 202 & \\
\hline \multirow{3}{*}{ HI-related queries are addressed in time. } & Disagree & 184 & 51 & 177 & 49 & 361 & \multirow{3}{*}{$<0.001$} \\
\hline & Neutral & 165 & 58.7 & 116 & 41.3 & 281 & \\
\hline & Agree & 56 & 33.3 & 112 & 66.7 & 168 & \\
\hline \multirow{3}{*}{ HI-related complaints are not addressed in time. } & Agree & 191 & 47.8 & 209 & 52.3 & 400 & \multirow{3}{*}{$<0.001$} \\
\hline & Neutral & 147 & 59 & 102 & 41 & 249 & \\
\hline & Disagree & 67 & 41.6 & 94 & 58.4 & 161 & \\
\hline \multirow{3}{*}{$\begin{array}{l}\text { It is not easy to take health services even after } \\
\text { enrollment. }\end{array}$} & Agree & 194 & 46 & 228 & 54 & 422 & \multirow{3}{*}{$<0.001$} \\
\hline & Neutral & 142 & 64.5 & 78 & 35.5 & 220 & \\
\hline & Disagree & 69 & 41.1 & 99 & 58.9 & 168 & \\
\hline \multirow{3}{*}{$\begin{array}{l}\text { Relatives or friends did not request/discuss for } \\
\text { enrollment. }\end{array}$} & Agree & 218 & 60.9 & 140 & 39.1 & 358 & \multirow{3}{*}{$<0.001$} \\
\hline & Neutral & 65 & 59.1 & 45 & 40.9 & 110 & \\
\hline & Disagree & 122 & 35.7 & 220 & 64.3 & 342 & \\
\hline \multirow{3}{*}{$\begin{array}{l}\text { HI related information is not adequate from } \\
\text { communication media. }\end{array}$} & Agree & 196 & 51.2 & 187 & 48.8 & 383 & \multirow{3}{*}{$<0.001$} \\
\hline & Neutral & 116 & 59.2 & 80 & 40.8 & 196 & \\
\hline & Disagree & 93 & 40.3 & 138 & 59.7 & 231 & \\
\hline
\end{tabular}




\section{Discussion}

The respondents overall agreed since the average score was 2.28, where one represents 'disagree', two 'neutral', and three 'agree' for positive statements and the mean score of the negative statements was 1.82 where one refers to 'agree', two 'neutral', and three 'disagree'. So it can be concluded that the respondents agreed in both positive and negative statements which showed that the perception was associated with enrollment in the HI program. Individuals' attitude influences decision making and behaviour change as well. Misconception or misinformation regarding $\mathrm{HI}$ could lead to negative attitudes and poor participation (Agyei-baffour et al., 2013) since most of the people were unaware of it (Health Research and Social Development Forum [HERD], 2016). Sometimes general prediction may be a failure that educated and wealthy people may be expected to have more knowledge as well as more enrollment but it does not always be true (Dixon et al., 2013). So it needs further study to predict.

Universal health coverage [UHC] is a global concern and targeted to be achieved by 2030 (Department of Health Services, 2019) and as per the national health policy and insurance policy (Ministry of Health (MoH), 2017; National Health Sector Programme, 2014) and constitutional mandate (The Constitution of Nepal, 2015), the government is under pressure to implement the $\mathrm{HI}$ program. But one-fourth of the people are still unknown about it (Acharya et al., 2019). It is challenging to implement since a mass population is still unaware of it. Therefore, positive attitude and perception are prerequisites for the success of the program (Yin et al., 2019).

A study shows that more than 13 percent of people did not want to enroll because they felt that they were healthy (Machlin \& Carper, 2005). In such instances, enrollment may be hard. HI packages should be competitive in the market. But in the context of Nepal, the government has initiated the program however $\mathrm{HI}$ from private sectors may influence the program since they may enter the community with a very creamy message which may attract the people quickly. Then, HIB may face the problem of poor enrollment and sustainability of the program since just over a quarter (28\%) service receivers were satisfied by the health services provided by the government compared to 56 percent from private sectors (Acharya et al., 2018; KOICA-Nepal Health Insurance Support Project [NHISP], 2014). The same observation was seen in Nigeria (Morrison \& Legaaga, 2017). In such a context, people may neglect the program considering poor satisfaction and negative attitude and perception of government health services.

Ghana's experience shows that $\mathrm{HI}$ subscribers from the rural area were more satisfied compared to subscribers from the urban area and access to mass media was found to be a significant predictor for perceived quality of health services (Nketiah-Amponsah et al., 2019). Another study shows that ever enrolled households were comparatively more negative towards $\mathrm{HI}$ compared to those who were never insured (Kwasi et al., 2018). It shows that even an insured family may have a negative perception of HI. The perception may be shaped by the experiences of treating differently while receiving the health services that lead to $\mathrm{HI}$ mechanism attractive or not attractive (Kwasi et al., 2018).

Quality health services need both a positive attitude and satisfaction of receivers as well as providers. A study from Morocco shows that most of the physicians were dissatisfied regarding mandatory HI (Zegraoui 
et al., 2018). Then how they provide quality services to the patients. It may create a patient's dissatisfaction and negative perception and attitude towards the HI program. Therefore, not only the receiver but also the provider should be satisfied with the program which may assure quality health services. Another study from India shows that 87 percent of nurses had favorable and 13 percent had unfavorable attitudes reading $\mathrm{HI}$ scheme (Kaklottar \& Sarate, 2019). Same results were observed in USA that most of the cancer survivors were satisfied with the quality and coverage of the insurance package (Park et al., 2016).

People's hesitation to participate in government-operated HI programs globally. An experience from Nigeria shows that just more than half [53\%] of the respondents agreed to participate in the $\mathrm{HI}$ scheme. Similarly, poor knowledge and a fair joining attitude were also observed (Olugbenga-Bello \& Adebimpe, 2010). But another study in that country shows that patients had high level of satisfaction regarding various health services received at hospitals (Garba et al., 2018).

A study in Uganda shows that 58 percent of the respondents did not know HI. Similarly, 43 percent of them did not know the importance, 43 percent of them knew about HI from insurance agents, 13 percent were covered by $\mathrm{HI}$ policy, 60 percent disagreed about the importance of $\mathrm{HI}$ to them, 78 percent expressed it as hard to understand, 55 percent agreed that $\mathrm{HI}$ is suitable for older people (Esther, 2018). All these data show that $\mathrm{HI}$ is considered as an asset of choice not a compulsion for all. Another study from Ethiopia shows that 55 percent of the households were satisfied with community-based $\mathrm{HI}$, which was significantly associated with the knowledge on $\mathrm{HI}$ of benefits packages (Kebede \& Geberetsadik, 2019) and suggested for information, education and communication campaigns to aware people.

Community-based $\mathrm{HI}$ has very a good impact in Bangladesh. It showed overall satisfaction in terms of health services however, it could be a chance of more improvement (Sarker et al., 2018). Such satisfaction makes people positive towards enrollment in $\mathrm{HI}$ and supports the global agenda of UHC. However, insurers were unsatisfied due to unclear terminology, high costs, and complexity of calculation of assets, unable to change the plan within a year. Such provision could make consumers anxious and feeling of wrong decisions that might lead to negative perception and attitude towards HI (Housten et al., 2016). A study from Ghana supports the study that there was a significant difference between the perception of health services quality between insured and non-insured clients where they expected more quality of health services than they received (Opoku, 2018). HI literacy and positive perception towards $\mathrm{HI}$ was a significant predictor for enrollment in $\mathrm{HI}$ and a low level of $\mathrm{HI}$ literacy was associated with the low level of enrollment (Norbeck, 2018) which also supports the study.

\section{Policy implication}

The study shows that positive perception towards HI leads to better enrollment in the HI program. Higher participation in the $\mathrm{HI}$ could lead to financial sustainability for health sectors and may fill the gap of inadequate budgets for healthcare and reduce the gap of utilizing healthcare services by rich and poor. It may lead to meet the targets of health and wellbeing for all, universal health coverage as well as ensuring the constitutional mandate of Nepal. Therefore, adequate information, education, and communication-related interventions are needed for better understanding and positive perception towards $\mathrm{HI}$. 


\section{Conclusion}

Perception and attitude play vital roles in $\mathrm{HI}$ especially in promoting $\mathrm{HI}$. As this study shows, the respondents agreed to most of the positive statements whereas they agreed on a few negative statements. Moreover, both the perception and attitude towards $\mathrm{HI}$ were found significantly associated with enrollment in HI. However, as the respondents expressed, they believed that enrollment in HI was not adequately managed to solve all types of health or disease-related problems. Nevertheless, various studies including this one showed that dissemination of appropriate and adequate information on $\mathrm{HI}$ was beneficial in making people positive about it.

\section{Acknowledgements}

The authors would like to thank the respondents for their time and response. They would also like to thank University Grants Commission [UGC], Nepal for providing PhD Fellowship.

\section{Declaration of Conflicting Interests}

The authors declared that there is no potential conflict of interest concerning research, authorship and or publication of this article.

\section{Funding}

The article is a part of PhD, partial financial support was received from UGC, Nepal as PhD Fellowship.

\section{Author contributions}

Conceptualization: Acharya, Devkota, Bhattarai, methodology: Acharya, Devkota; Software: Acharya; Validation: Acharya, Devkota; Formal Analysis: Acharya, Devkota; Investigation: Acharya, Devkota, Bhattarai Data Curation: Acharya, Bhattarai; Writing - Original Draft: Acharya; Writing - Review \& Editing: Acharya, Devkota, Bhattarai; Visualization: Acharya, Bhattarai; Supervision: Devkota

\section{Disclosure Statement / Conflict of interest}

The authors declare no conflict of interest.

\section{Ethical statement}

The research proposal was reviewed for ethical approval from Nepal Health Research Council [Ref. 1807, Reg. no. 473/2017].

\section{Data deposition}

Data will be available upon reasonable request from the corresponding author.

\section{Author ORCID information}

Devaraj Acharya, ORCID: 0000-0003-0847-4836; Bhimsen Devkota, ORCID: 0000-0001-7191-801X; Radha Bhattarai, ORCID: 0000-0002-4003-047X

\section{References}

Acharya, D. (2020). Information, education, and communication for enrolment in health insurance in Nepal. An unpublished PhD dissertation, Faculty of Education, Tribhuvan University.

Acharya, D., Devkota, B., \& Adhikari, R. (2018). Willingness to pay for family health insurance : Evidence from Baglung and Kailali districts of Nepal. Global Journal of Health Science, 10(12), 144-155. https://doi.org/10.5539/gjhs.v10n12p144

Acharya, D., Devkota, B., Gautam, K., \& Bhattarai, R. (2020). Association of information, education, and communication with enrolment in health insurance: a case of Nepal. Archives of Public Health, 78(135), 1-13. https://doi.org/10.1186/s13690-020-00518-8

Acharya, D., Devkota, B., \& Wagle, B. P. (2019). Factors associated to the enrollment in health insurance: An 
experience from selected districts of Nepal. Asian Social Science, 15(2), 90-99.

https://doi.org/10.5539/ass.v15n2p90

Adewale, B., Adeneye, A. K., Ezeugwu, S. M. C., Afocha, E. E., \& Musa, A. Z. (2016). A preliminary study on enrollees perception and experiences of National Health Insurance Scheme in Lagos State, Nigeria. International Journal of Tropical Disease and Health, 18(3), 1-14. https://doi.org/10.9734/IJTDH/2016/27309

Adewole, D. A., Adebayo, A. M., Udeh, E. I., Shaahu, V. N., \& Dairo, M. D. (2015). Payment for health care and perception of the National Health Insurance Scheme in a rural area in Southwest Nigeria. American Journal of Tropical Medicine and Hygiene, 93(3), 648-654. https://doi.org/10.4269/ajtmh.14-0245

Agustin, D., \& Laksmono, B. S. (2019). Satisfaction of elderly patients participating in health insurance and seeking health services at the Sukmajaya Community Health Center in Depok - Expectations and realities: Pilot Study. Journal of International Dental and Medical Research, 12(1), 278-285.

Agyei-baffour, P., Oppong, R., \& Boateng, D. (2013). Knowledge , perceptions and expectations of capitation payment system in a health insurance setting : A repeated survey of clients and health providers in Kumasi , Ghana. BMC Public Health, 13(1220), 1-9. https://doi.org/10.1186/1471-2458-13-1220

AlTarawneh, R. K., Etawi, W. . M., Al-Wrikat, H. A., Al-Hrasees, O. A., \& AlTarawneh, I. K. (2017). The degree of the satisfaction of parents about health insurance services presented to the persons with physical and health impairments in Jordan Ministry of Education. American International Journal of Social Science, 6(4), 49-58.

Amo-adjei, J., Anku, P. J., Amo, H. F., \& Effah, M. O. (2016). Perception of quality of health delivery and health insurance subscription in Ghana. BMC Health Services Research, 16(317), 1-11.

https://doi.org/10.1186/s12913-016-1602-4

Ballon, B. C., \& Skinner, W. (2008). "Attitude is a little thing that makes a big difference": Reflection techniques for addiction psychiatry training. Academic Psychiatry, 32(3), 218-224.

https://doi.org/10.1176/appi.ap.32.3.218

Central Bureau of Statistics. (2014). Statistical pocket book of Nepal. Government of Nepal, National Planning Commission Secretariat, Central Bureau of Statistics. https://cbs.gov.np/wpcontent/upLoads/2019/02/Statistical-Pocket-Book-2014.pdf

Department of Health Services. (2019). Annual Report: Department of Health Services 2074/75 (2017/18). https://dohs.gov.np/wp-content/uploads/2019/07/Annual_Report_2074-751.pdf

Dixon, J., Tenkorang, E. Y., \& Luginaah, I. (2013). Ghana's National Health Insurance Scheme : A national level investigation of members' perceptions of service provision. BMC International Health and Human Rights, 13(35). https://doi.org/10.1186/1472-698X-13-35

Esther, N. (2018). Knowledge, attitude and practices towards uptake of health insurance in Uganda. Makerere University.

Garba, M. R., Gadanya, M. A., Iliyasu, Z., \& Gajida, A. U. (2018). Comparative study of patients ' satisfaction between national health insurance scheme - insured and un-insured patients attending a Northern Nigerian Tertiary Hospital. Nigerian Journal of Basic and Clinical Sciences, 15(2), 118-126. 
https://doi.org/10.4103/njbcs.njbcs

Hair, J. F., Black, W. C., Babin, B. J., \& Anderson, R. E. (2014). Multivariate data analysis (7th ed.). Pearson Education Limited.

Health Research and Social Development Forum [HERD]. (2016). Keeping under the umbrella: Universal health coverage (Issue June). HERD. www.herd.org.np

Housten, A. J., Furtado, K., Kaphingst, K. A., Kebodeaux, C., Mcbride, T., Cusanno, B., \& Politi, M. C. (2016). Stakeholders' perceptions of ways to support decisions about health insurance marketplace enrollment : A qualitative study. BMC Health Services Research, 16(634), 1-11. https://doi.org/10.1186/s12913-016$1890-8$

Joshi, P., Solanki, J., Chaudhary, P., Jadoun, D. S., Mishra, P., \& Sharma, P. (2019). Knowledge and perceptions about dental health insurance among dental practitioners of Jaipur City. Journal of Indian Association of Public Health Dentistry, 17(2), 130-135. https://doi.org/10.4103/jiaphd.jiaphd

Kaklottar, S. A., \& Sarate, S. (2019). A study to assess knowledge and attitude regarding selected government health insurance schemes among Staff Nurse in selected hospitals of Ahmedabad District : A main study. Open Access Library Journal, 6(e5128), 1-5. https://doi.org/10.4236/oalib.1105128

Kebede, K. M., \& Geberetsadik, S. M. (2019). Household satisfaction with community- based health insurance scheme and associated factors in piloted Sheko district; Southwest Ethiopia. PLOS ONE, 14(5), 1-13.

KOICA-Nepal Health Insurance Support Project [NHISP]. (2014). Comprehensive district assessment for health insurance in Kailali district.

KOICA/HIMAL Project. (2012). Community-based health insurance: Implementation manual.

Kothari, C. R. (2004). Research methodology: Methods and techniques (2nd ed.). New Age International (P) Limited.

Kwasi, S., Duku, O., Nketiah-amponsah, E., Janssens, W., \& Pradhan, M. (2018). Perceptions of healthcare quality in Ghana: Does health insurance status matter ? PLOS ONE, 13(1), 1-17. https://doi.org/10.1371/journal.pone.0190911

Machlin, S., \& Carper, K. (2005). Attitudes toward health insurance among adults age 18 and over (Issue July). Agency for Health Research and Quality.

Maina, J. M., Kithuka, P., \& Tororei, S. (2016). Perceptions and uptake of health insurance for maternal care in rural Kenya: A cross sectional study. Pan African Medical Journal, 23(125), 1-10.

https://doi.org/10.11604/pamj.2016.23.125.8936

Mathur, T., Paul, U. K., Prasad, H. N., \& Das, S. C. (2015). Understanding perception and factors influencing private voluntary health insurance policy subscription in the Lucknow region. International Journal of Health Policy and Management, 4(2), 75-83. https://doi.org/10.15171/ijhpm.2015.08

Ministry of Health (MoH). (2017). National Health Policy, 2017 - (First Draft) (pp. 1-39). http://dohs.gov.np/wp-content/uploads/2014/04/NHP-2074_policy-01.pdf

Ministry of Health, New ERA, \& ICF. (2017). Nepal Demographic and Health Survey 2016. www.dhsprogram.com/pubs/pdf/fr336/fr336.pdf

Morrison, T., \& Legaaga, J. (2017). Preference and customers' satisfaction with private health insurance 
services in Cross River State, Nigeria. Equatorial Journal of Marketing and Insurance Policy, 2(3), 29-37.

Nadpara, P. A. (2009). Health status and attitudes towards health insurance in MEPs sample population.

International Society for Pharmacoeconomics and Outcomes Research, 12(3), A90.

https://doi.org/10.1016/S1098-3015(10)73516-6

Naing, L., Winn, T., \& Rusli, B. N. (2006). Practical issues in calculating the sample size for prevalence studies.

Archives of Orofacial Sciences, 1(Ci), 9-14. https://doi.org/10.1146/annurev.psych.60.110707.163629

National Health Sector Programme. (2014). National Health Policy 2014. http://nhsp.org.np/wp-

content/uploads/2016/08/New-health-policy-2014-Unofficial-translation.pdf

Nepal Health Research Council. (2011). National ethical guidelines for health research in Nepal and standard operating procedures (Issue January). Nepal Health Research Council.

The Constitution of Nepal, (2015). https://www.lawcommission.gov.np/en/wp-content/

uploads/2021/01/Constitution-of-Nepal.pdf

Nketiah-Amponsah, E., Alhassan, R. K., Ampaw, S., \& Abuosi, A. (2019). Subscribers' perception of quality of services provided by Ghana's National Health Insurance Scheme - What are the correlates ? BMC Health Services Research, 19(196), 1-11. https://doi.org/10.1186/s12913-019-4023-3

Norbeck, A. J. (2018). Health insurance literacy impacts on enrollment and satisfaction with health insurance. Walden University.

Olugbenga-Bello, A., \& Adebimpe, W. (2010). Knowledge and attitude of civil servants in Osun State, Southwestern Nigeria towards the National Health Insurance. Nigerian Journal of Clinical Practice, 13(4), 421-426.

Opoku, T. (2018). Health insurance status and client perception of quality of care at Kwahu Government Hospital (Issue 10308885). University of Ghana.

Orr, J. W., Naumann, W. R., \& Escobar, P. (2008). "Attitude is a little thing that makes a big differences" Winston Churchill. Gyanecologic Oncology, 109(1), 147-151. https://doi.org/ 10.1016/j.ygyno.2007.12.025

Otto-sobotka, F., Peplies, J., \& Timmer, A. (2019). Modeling determinants of satisfaction with health care in youth with in $\mathrm{fl}$ ammatory bowel disease part 2: Semiparametric distributional regression. Clinical Epidemiology, 11, 403-417. https://doi.org/10.2147/CLEP.S191458

Park, E. R., Kirchhoff, A. C., Zallen, J. P., Weissman, J. S., Pajolek, H., Mertens, A. C., Armstrong, G. T., Robison, L. L., Donelan, K., Recklitis, C. J., Diller, L. R., \& Kuhlthau, K. A. (2016). Childhood cancer survivor study participants' perceptions and knowledge of health insurance coverage: implications for the Affordable Care Act. Journal of Cancer Survivorship, 6(3), 251-259. https://doi.org/10.1007/s11764-012-0225y.Childhood

Sarker, A. R., Sultana, M., Ahmed, S., Mahumud, R. A., Morton, A., \& Khan, J. A. M. (2018). Clients' experience and satisfaction of utilizing healthcare services in a community based health insurance program in Bangladesh. International Journal of Environmental Research and Public Health, 15(1637). https://doi.org/10.3390/ijerph15081637

Subedi, L., Regmi, M. C., \& Giri, Y. (2018). Assessment of community based health insurance in Sunsari District. 
Kathmandu University Medical Journal, 16(61), 53-59. http://www.kumj.com.np/issue/61/53-59.pdf Water Aid. (n.d.). Behaviour Change Theory -Outline [Module I] (pp. 1-12).

https://www.Ishtm.ac.uk/media/11191

Yin, X., Abruquah, L. A., \& Ding, Y. (2019). Dynamics of life satisfaction among rural elderly in China : The role of health insurance policies and intergenerational relationships. Sustainability, 11(701), 1-19.

https://doi.org/10.3390/su11030701

Zegraoui, S., Cheikh, A., Bouatia, M., Ajaja, M. R., Naji, S., \& Hassani, A. El. (2018). Knowledge, attitudes and practices of the liberal doctors in relation to the national convention signed in the framework of mandatory health insurance in Morocco: A cross-sectional study. Pan African Medical Journal, 29(139), 1-7. https://doi.org/10.11604/pamj.2018.29.139.14407 